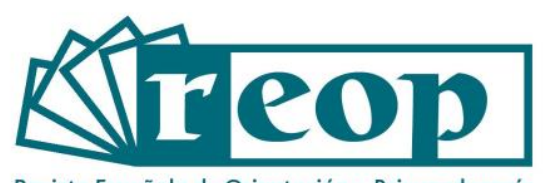

Revista Española de Orientación y Psicopedagogía

\title{
Turienzo, R. (2019). Haz que suceda. Un sistema de herramientas revolucionario para alcanzar tus objetivos de una vez por todas. Editorial Alienta, 207 páginas. ISBN: 978-84-17568-74-0.
}

Esta obra, con carácter eminentemente práctico, es elaborada por Rubén Turienzo, autor de doce libros, y consultor con años de experiencia y gran reputación en todo el mundo, por su amplio bagaje en ámbitos como el comportamiento humano y las planificaciones estratégicas.

Lo más impresionante y bello de la obra es su carácter profesional enfocado en lo personal, a través de propuestas que ayudan o intentan ayudar a la persona que lee el manual a conseguir sus objetivos, tanto personales como profesionales, lo cual repercute en una mejor vida y con ello, en la consecución de su propio éxito, siempre con el lema \#HazQueSuceda.

Es un práctico manual que destaca por su carácter funcional y operativo, a través del aporte de una serie de herramientas y técnicas con carácter auto aplicado, útiles para planificar y poner en marcha en intervenciones en acción tutorial y procesos de orientación académica y profesional, de la misma manera que es aplicable en procesos de autorientación.

Con esto, se invita a su lectura no sólo a profesionales de la orientación, quienes pueden emplearlo en sesiones individualizadas de orientación o en talleres grupales, si no, también a estudiantes en proceso de transición académico-profesional, personas en desempleo que necesiten llevar a cabo un proceso esquematizado para cumplir sus objetivos laborales, y a cualquier persona que necesite una mejora profesional. De igual modo, en nuestra opinión, es un recurso imprescindible para futuros/as profesionales en procesos de reinversión profesional, personas en fases iniciales de emprendimiento, e incluso para emprendedores consolidados con objetivos de mejora en sus proyectos e ideas de negocio.

El libro se compone de siete partes claramente diferenciadas, seis de las cuales son las fases correspondientes a un itinerario programado y contrastado para alcanzar los objetivos propuestos, con una secuencia ordenada. La primera de ellas intenta dar respuesta al "qué", es decir, encontrar y definir el objetivo (objetivo estratégico); seguida de esta primera parte, encontramos el "por qué", aludiendo al motivo o propósito (motivación estratégica); la tercera parte hace referencia al "quién", centrándose en la identificación de recursos (recursos estratégicos); la cuarta parte refiere al "con quién", es decir, con quien contamos para poder cumplir nuestro objetivo (plan estratégico social); la quinta parte alude al "cómo", adentrándose en el dibujo del plan de acción (plan táctico operativo); la sexta parte nos habla del "cuándo", y aquí entra en juego la planificación temporal, hacer un seguimiento del plan de acción propuesto e, incluso, rectificar si es necesario (táctica temporal). El último capítulo, aunque realmente no es una fase del plan de 
acción, consiste en compartir todos aquellos pasos que se han seguido para poder cumplir el objetivo.

El contenido de la obra está ilustrado desde frases para pensar y apoyado con imágenes, gráficos, enlaces web, y recursos destacados para complementar el proceso de trabajo de cada fase. Al final, la obra incluye un apartado denominado "biblioteca para hacer que suceda" compuesto por un conjunto de referencias específicas para cada una de las fases o partes mencionadas anteriormente, y que sirven de guía y apoyo para el buen desarrollo del plan de acción. Para finalizar, encontramos un apartado denominado "canciones para hacer que suceda". Estos recursos nos parecen de mucha utilidad en procesos de formación en acción tutorial con nuestros/as estudiantes, y también en intervenciones orientadoras en el contexto universitario, aunque también en otros sean formales o no formales.

En líneas generales este cuaderno de trabajo, como menciona el autor, nos ayuda a realizar un recorrido teórico-práctico por todas las fases necesarias para ayudar a cumplir con nuestros objetivos personales o profesionales. Esto es especialmente relevante en los momentos que vivimos donde muchas personas han perdido sus empleos o tienen que reinventar sus carreras, todo ello provocado por la crisis sanitaria del COVID19. Esta obra ayuda a la persona a tomar conciencia de sus necesidades y también de sus oportunidades.

\author{
Carolina Romero García \\ Profesora Sustituta Interina \\ Doctoranda en Educación \\ Universidad de Sevilla
}

\title{
Cómo citar esta recensión:
}

Romero García, C. (2021). Turienzo, R. (2019). Haz que suceda. Un sistema de herramientas revolucionario para alcanzar tus objetivos de una vez por todas. Editorial Alienta, 207 páginas. ISBN: 978-84-17568-74-0 [Reseña] Revista Española de Orientación y Psicopedagogía, 32(2), 170-171. https://doi.org/10.5944/reop.vol.32.num.2.2021.31285 